\title{
Malnutrition and cancer, diagnosis and treatment
}

\author{
Angelika Beirer
}

Received: 23 September 2020 / Accepted: 17 December 2020 / Published online: 1 April 2021

(C) The Author(s) 2021

\begin{abstract}
Summary
Background The prevalence of malnutrition in cancer patients ranges from about $20 \%$ to more than $70 \%$. However, $10-20 \%$ of cancer patients' deaths are related to malnutrition, not the malignancy itself. To reverse the pattern of weight loss, improve the patients' quality of life, reduce the treatment toxicity, the psychological stress and the risk of mortality, the diagnosis of malnutrition should be made as early as possible to facilitate the best possible treatment.

Methods A systematic literature search was conducted following guidelines of ESPEN (European Society for Clinical Nutrition), DGEM (German Society for Nutritional Medicine) and ASPEN (American Society for Parenteral and Enteral Nutrition).

Results and conclusion To assess the risk of malnutrition, all cancer patients should be screened regularly with a valid screening tool (e.g., MUST [Malnutrition Universal Screening Tool], NRS [Nutritional Risk Screening] or PG-SGA [Scored Patient-Generated Subjective Global Assessment]). If risk of malnutrition is present, adequate nutritional therapy is recommended to stop involuntary weight loss. Patients should engage in exercise to maintain and improve muscle mass, strength and function. They should be offered regular dietetic counselling, and their muscle depletion should be monitored by determining fat-free mass. As cachectic patients in particular are at risk, the presence of cachexia should also be recognized at an early stage. Three consensus-based definitions are widely accepted: Fearon et al. and the EPCRC (European Palliative Care Research Collaborative) propose definitions specifically for cancer
\end{abstract}

Mag. A. Beirer, Bsc. $(\bowtie)$

FH St. Pölten, Matthias Corvinus-Straße 15, 3100 St. Pölten, Austria

angelika.beirer@fhstp.ac.at cachexia, while Evans et al. put forward a definition for cachexia associated with all types of underlying chronic diseases. However, if there is a cancer cachexia diagnosis, additional pharmacological and psychological treatment should be considered.

Keywords Cachexia - Sarcopenia - Obese cancer patients · Involuntary weight loss · Oncology

\section{Introduction}

Malnutrition means a significant loss of weight and body resources, which results in an impairment of quality of life and prognosis [1]. Worldwide studies show that the prevalence of malnutrition in cancer patients ranges from about $20 \%$ to more than $70 \%$. However, $10-20 \%$ of cancer patients' deaths are related to malnutrition, not the malignancy itself. Although certain cancer patient groups are more vulnerable to malnutrition than others, many of these patients are never treated for malnutrition. The risk of malnutrition is particularly evident after gastrointestinal tumor surgery such as gastrectomy, pancreatectomy, small bowel surgery, or high-lying stoma and therapy-induced diarrhea, whereby $80 \%$ of patients with these tumor entities, and $30 \%$ of all cancer patients have already lost weight prior to diagnosis [1].

\section{Causes of malnutrition}

In an interactive network, mutually reinforcing factors are understood to be the causes of malnutrition in cancer patients $[1,2]$.

Gastrointestinal disorders such as nausea or diarrhea, changes in smell and taste, drug side effects, psychological stress and pain can all lead to a reduced food intake and consequently to weight loss. This in turn leads not only to a weakening of the immune sys- 
tem but also to muscle loss, which is increased both by the inflammation of the tumor stroma and by the reduced mobility. Systemic inflammation processes and the loss of cell and muscle mass associated with weight loss cause fatigue, which in turn leads to reduced physical activity [1].

Immunologic, metabolic and clinical phenomena are related. The upregulated innate immune response causes systemic inflammation which leads to different symptoms such as anorexia, weight loss and reduced physical function, as well as fatigue, pain and depression [2]. Inflammatory factors like TNF- $\alpha$ (Tumor necrosis factor-alpha), IL-6 (Interleukin-6) and IL-1 (Interleukin-1) released by the tumor itself affect muscle, brain, liver and fat functions. This systemic inflammation results in:

- Altered CNS (central nervous system) signals causing anorexia

- Changes in the liver metabolism repressing drug clearance and raising the risk of chemotherapyrelated toxicity

- Muscle wasting, a reduction of muscle mass and strength

- Depletion of fat deposits [2].

\section{Diagnosis of malnutrition and cachexia}

All patients with unwanted weight loss should be examined to determine the origin. It is important not only to interview the patient, but also to take body weight and size measurements to ensure accurate data, and to identify the presence of edemas, ascites or pleural effusion.

It is advised to use a valid screening tool in order to determine the risk of malnutrition. The use of MUST (Malnutrition Universal Screening Tool), NRS (Nutritional Risk Screening) or PG-SGA (Scored Patient-Generated Subjective Global Assessment) should be considered [3, 4]. Age is assumed to be an additional risk factor for NRS and PG-SGA.

Jensen et al. distinguish between starvation-related malnutrition (which means chronic starvation without inflammation), chronic disease-related malnutrition (with chronic inflammation and of mild to moderate degree), and acute disease- or injury-related malnutrition (which involves acute inflammation and is of severe degree) [5].

As described in the DGEM guideline of clinical nutrition, starvation-related malnutrition is the result of chronic undernourishment in patients showing no signs of inflammation.

General criteria to diagnose disease-related malnutrition are [6]:

- Body mass index (BMI) $<18.5 \mathrm{~kg} / \mathrm{m}^{2}$ or

- Involuntary weight loss $>10 \%$ in the last 3-6 months or

- $\mathrm{BMI}<20 \mathrm{~kg} / \mathrm{m}^{2}$ and unwanted weight loss $>5 \%$ in the last 3-6 months.
Starvation lasting for more than seven days is defined as an independent criterion for risk of malnutrition.

The above criteria also apply to obese patients [7]: a 40 -year-old person weighing $80 \mathrm{~kg}$, with a height of $160 \mathrm{~cm}$, a BMI of 31 and a weight loss of $10 \%$ is also malnourished, although still obese with a BMI of 28 . Minor weight loss is often not mentioned in this group of patients and not seriously considered [7].

As a meta-analysis of Winter et al. shows that the all-cause mortality risk increases in older people with a BMI $<23$ [8], the limit for the BMI to diagnose the risk of malnutrition may need to be set higher for patients older than 65 . In the recommendations statement of the European Society of Clinical Nutrition (ESPEN), the use of a higher cut-off point of 22 for elderly patients is also suggested [9]. Ideal reference areas for the BMI for this group from 22-26.99 [10] and 24-29 [11] are already mentioned in the literature.

Cachectic patients have a particularly poor prognosis, and more than $10 \%$ of all cancer patients die with or due to this condition [12].

In an international consensus, Fearon et al. defined cancer cachexia as "a multifactorial syndrome characterized by ongoing loss of skeletal muscle mass (with or without loss of fat mass) that cannot be fully reversed by conventional nutritional support and leads to progressive functional impairment" $[13,14]$.

Unwanted weight loss, muscle atrophy, fatigue, weakness, a significant loss of appetite, and the presence of an inflammation are characteristics of cachexia [6].

Evans et al. [15] describes the following criteria to identify cachexia:

Weight loss of $\geq 5 \%$ in $\leq 12$ months due to a preexisting condition, plus three of the following criteria:

- Reduced muscle strength

- Fatigue

- Anorexia

- Lower fat-free mass index (fat-free mass $[\mathrm{kg}] /$ body height $\left.^{2}\left[\mathrm{~m}^{2}\right]\right)$

- Abnormal blood chemistry

- CRP > $5.0 \mathrm{mg} / \mathrm{L}, \mathrm{IL}-6>4.0 \mathrm{pg} / \mathrm{mL}$

- Anemia $(\mathrm{Hb}<12 \mathrm{~g} / \mathrm{dL})$

- Albumin $(<32 \mathrm{~g} / \mathrm{L})$.

As this definition is not specific to cancer, other consensus-based definitions for cancer cachexia have been proposed [13]. There is currently no international standard guideline treatment as there is no single widely accepted definition and assessment of cancer cachexia. Particularly regarding cancer cachexia, two consensus-based definitions by Fearon et al. and the EPCRC (European Palliative Care Research Collaborative) can be used.

Fearon et al. proposed $\geq 2$ out of the following 3 criteria [16]:

- Weight loss ( $\geq 10 \%)$

- Low food intake ( $\leq 1500 \mathrm{kcal} /$ day) 


\section{short review}

\section{SCREEN EVERY CANCER PATIENT WITH A VALID SCREENING TOOL TO VERIFY DISEASE-RELATED MALNUTRITION}

$B M I<18.5 \mathrm{~kg} / \mathrm{m}^{2}$ or unwanted weight loss $>10 \%$ in the last $3-6$ months

OR

$\mathrm{BMI}<20 \mathrm{~kg} / \mathrm{m}^{2}$ and unwanted weight loss $>5 \%$ in the last 3-6 months [6]

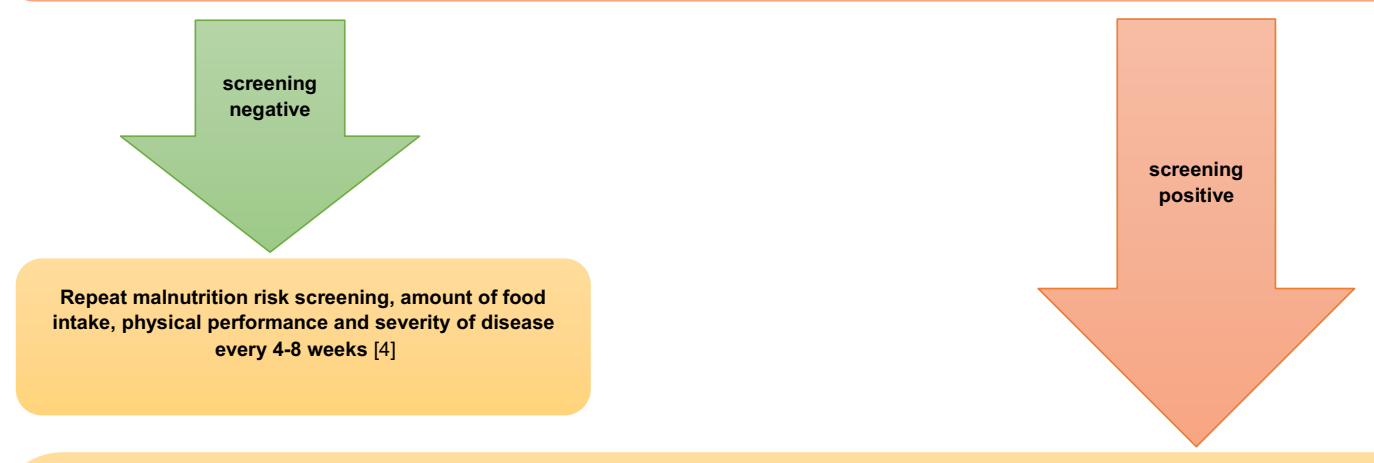

CACHEXIA

$\geq 2$ out of the following 3 criteria [16]:

$\checkmark \quad$ Weight loss $(\geq 10 \%)$

$\checkmark \quad$ Low food intake $(\leq 1500 \mathrm{kcal} / \mathrm{d})$

$\checkmark$ Systemic inflammation (C-reactive protein [CRP] $\geq 10 \mathrm{mg} / \mathrm{L}$ )

$\mathrm{OR}$

Weight loss $>5 \%$ over past 6 months without starvation and/or weight loss $>2 \%$ and $B M \mid<20$ and/or weight loss $>2 \%$ and sarcopenia [14]

Stop involuntary weight loss $[7]$ :

- Prepare a nutritional protocol covering 2-3 days and calculate it with the help of IT in order to carry out targeted nutritional therapy [7][1]

- Increase energy intake [21]

- Offer regular small meals [21]

- Allow flexible size, frequency and type of meals [21]

- Reduce or eliminate dietetic restrictions if possible [4]

- Hydration [21]

- Hydration [21]

therapy [21]

- Integrate energy and protein additives [4][21][2]

- Provide oral nutritional supplements and/or

enteral/parenteral nutrition if needed [21][2][7]

$\checkmark \quad$ Engage in exercise to maintain and improve muscle mass, strength and function [13]

$\checkmark \quad$ Schedule regular dietetic counselling [21]

$\checkmark \quad$ Determine fat-free mass and monitormuscle depletion [19][13]
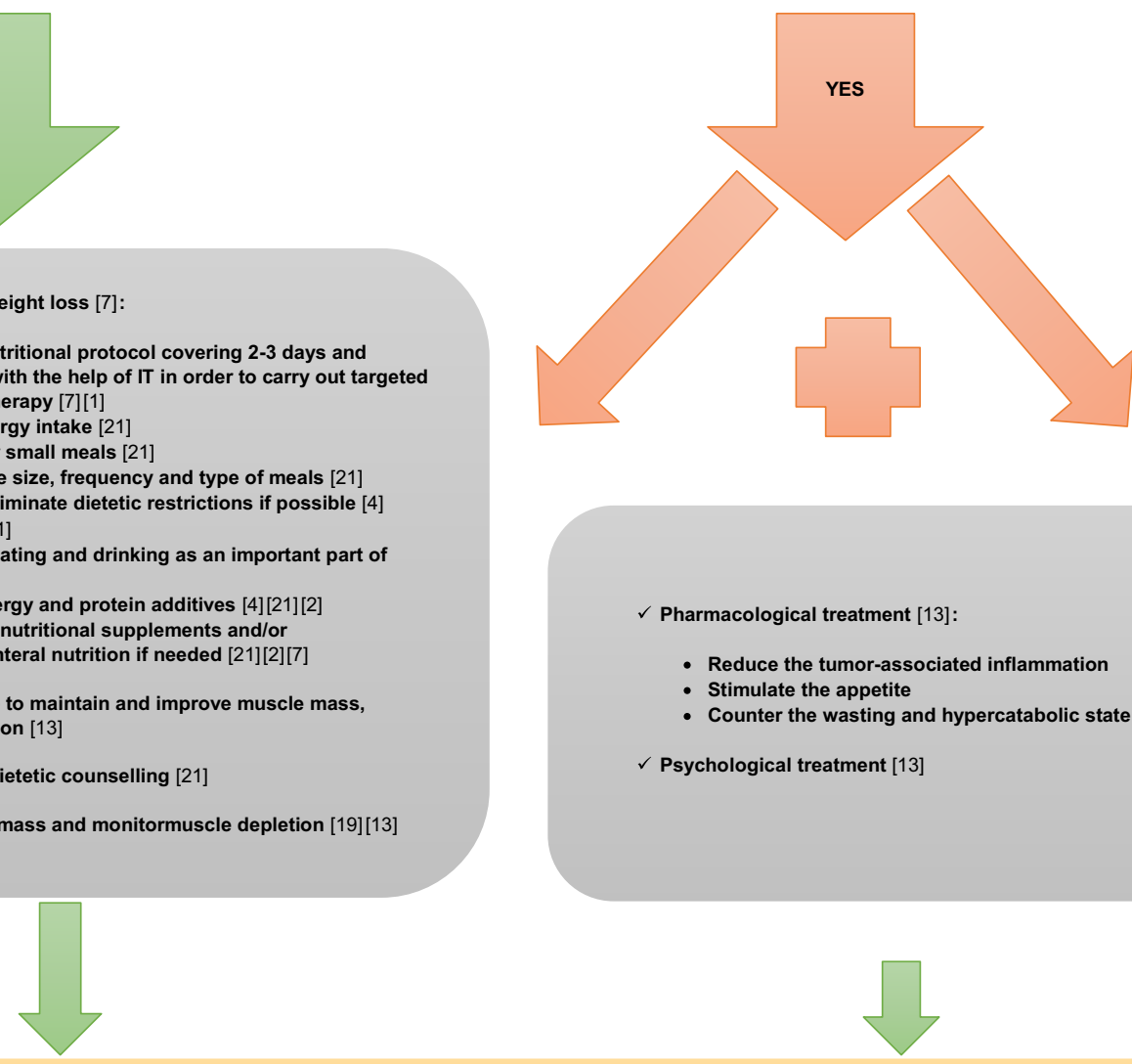

$\checkmark$ Pharmacological treatment [13]:

- Reduce the tumor-associated inflammation

- Stimulate the appetite

- Counter the wasting and hypercatabolic state

$\checkmark$ Psychological treatment [13]

REGULAR AFTERCARE AND CHECK-UP [21]

Fig. 1 Diagnosis and treatment. Regular aftercare and check-up [20]. BMI body mass index 


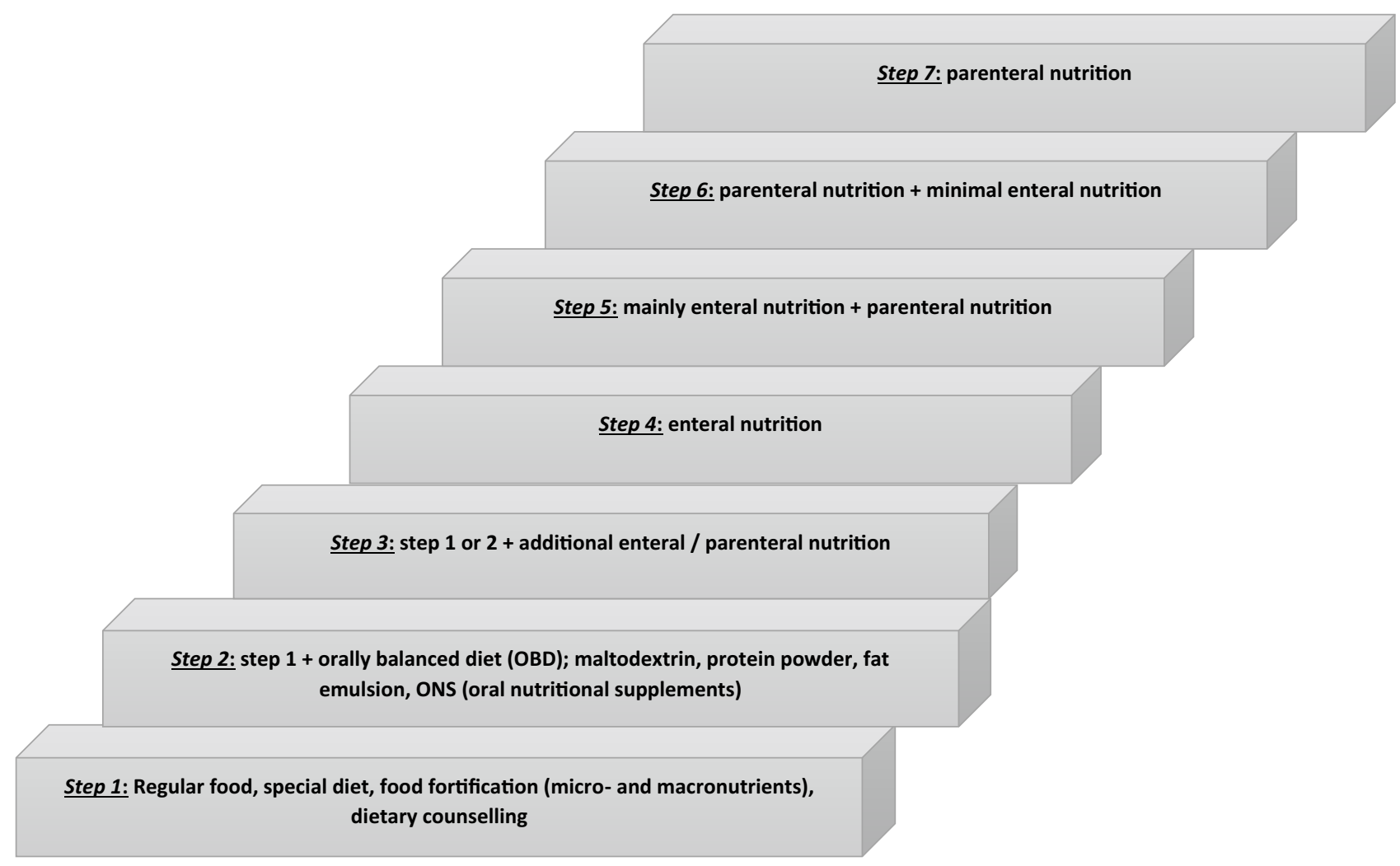

Fig. 2 Always pay attention to refeeding in regard to enteral/parenteral nutrition

- Systemic inflammation (C-reactive protein [CRP] $\geq 10 \mathrm{mg} / \mathrm{L}$ ).

EPCRC (European Palliative Care Research Collaborative) proposed [14]:

- Weight loss $>5 \%$ over past 6 months without starvation and/or

- Weight loss $>2 \%$ and BMI $<20$ and/or

- Weight loss $>2 \%$ and sarcopenia.

Cruz-Jentoft et al. defined sarcopenia as a "syndrome characterised by progressive and generalised loss of skeletal muscle mass and strength with a risk of adverse outcomes such as physical disability, poor quality of life, and death [17]". The SCWD (task force of the Society for Sarcopenia, Cachexia and Wasting Disorders) recommends to screen for sarcopenia using a simple tool like the SARC-F. It is necessary to diagnose sarcopenia using following examinations: grip strength or chair stand and-if possible-a measurement of fat-free mass [18]. DXA (dual X-ray absorptiometry), MRI (magnetic resonance imaging), CT (computed tomography), US (ultrasound) and BIA (bioelectrical impedance analysis) can be used to determine fat-free mass and to monitor muscle depletion. DXA seems to be the most valid method but the BIA method is widely used due to its simplicity and low cost ([13, 19]; Fig. 1).

\section{Treatment of malnutrition and cachexia}

If risk of malnutrition is present, nutritional assessment is required to improve physical performance, metabolism, tolerability of antitumor therapies, quality of life, and course of disease. Nutritional counselling includes a recording of food intake (computeraided evaluation of food log), nutritionally relevant symptoms, body and muscle mass, systemic inflammation, and performance status [4].

If the caloric intake is less than $60 \%$ of the estimated requirements over a period of $1-2$ weeks, or if eating is not possible for a week, insufficient nutritional intake is validated [2]. High-quality medical nutritional intervention is provided by dieticians. The structure of the therapeutic interventions is shown by the following scheme described by Valentini et al. ([6]; Fig. 2):

Enteral or parenteral nutrition is indicated in case of inadequate nutritional intake (less than $500 \mathrm{kcal} /$ day for a couple of days or oral nutritional intake of less than $75 \%$ of TEE for 1-2 weeks), and if an improvement of quality of life, increased longevity and greater patient comfort can be expected ([1, 4]; Table 1).

The main goals in the treatment of cachexia are improvements in lean body mass, resting energy expenditure, fatigue, anorexia, quality of life, and performance status as well as a reduction of the tumorassociated inflammation [13]. Appetite stimulants, 
Table 1 Recommended energy and nutrient intake of malnourished cancer patients

Energy Use indirect calorimetry to determine resting energy expenditure if available, or estimate REE with formulas like Harris-Benedict, Schofield or WHO. Assume a physical activity level of 1.0-1.5 [4]

Protein $\quad 1.2-1.5 \mathrm{~g} / \mathrm{kg}$ body weight per day to maintain or restore lean body mass [4] Protein amounts of more than $2 \mathrm{~g} / \mathrm{kg}$ body weight per day are of no benefit [4]

Enrich with supplements (e.g. protein powder, ONS)

Choose foods with a high biological value

Offer immunomodulatory enteral formulas containing arginine and nucleotides to patients undergoing cancer surgery [2]

Fat Intake should amount to at

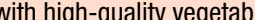
least $35 \%$ of TEE [4] oils as well as butter, cream or In case of insulin resistance other fatty dairy products or if a higher energy density Fish oil (omega-3 fatty acids) is is required, up to $50 \%$ of suggested to improve appetite, oral TEE may be considered [4] intake, lean body mass and body weight [2]

REE resting energy expenditure, WHO World Health Organization, ONS oral nutritional supplement, TEE total energy expenditure

Table 2 Pharmacological treatment options

\begin{tabular}{|c|c|c|}
\hline Drug & Effects & Side effects \\
\hline Prokinetics & $\begin{array}{l}\text { Appetite stimulating, } \\
\text { Reduced sickness [7] }\end{array}$ & $\begin{array}{l}\text { No effects on body } \\
\text { weight [7] }\end{array}$ \\
\hline Gestagenes & $\begin{array}{l}\text { Appetite stimulating } \\
\text { Weight gain }[4,7]\end{array}$ & $\begin{array}{l}\text { Adrenal insufficiency } \\
\text { Thromboembolism } \\
\text { Impotence }[4,7]\end{array}$ \\
\hline $\begin{array}{l}\text { Glucocorti- } \\
\text { coids }\end{array}$ & $\begin{array}{l}\text { Appetite stimulating } \\
\text { Reduced systemic inflammation } \\
\text { Increase in ingestion, quality of life, } \\
\text { physical performance and well-being } \\
{[4,7,13]}\end{array}$ & $\begin{array}{l}\text { Cushing syndrome } \\
\text { Short-lived positive } \\
\text { effects }[4,7,13]\end{array}$ \\
\hline $\begin{array}{l}\text { Canna- } \\
\text { binoids }\end{array}$ & $\begin{array}{l}\text { Appetite stimulating } \\
\text { Reduced dysgeusia }[4,7,13]\end{array}$ & $\begin{array}{l}\text { Neuropsychological } \\
\text { side effects }[4,7,13]\end{array}$ \\
\hline $\begin{array}{l}\text { Eicosapen- } \\
\text { taenoic acid }\end{array}$ & $\begin{array}{l}\text { Appetite stimulating } \\
\text { Reduced systemic inflammation } \\
\text { Weight gain } \\
\text { Increase in ingestion and quality of life } \\
\text { [7] }\end{array}$ & $\begin{array}{l}\text { Under high-dose } \\
\text { therapy reduced blood } \\
\text { coagulation [7] }\end{array}$ \\
\hline $\begin{array}{l}\text { Nonsteroidal } \\
\text { antirheumat- } \\
\text { ics }\end{array}$ & $\begin{array}{l}\text { Reduced systemic inflammation, } \\
\text { Weight gain } \\
\text { Increase of physical performance [7, } \\
\text { 13] }\end{array}$ & $\begin{array}{l}\text { Gastroenteral bleeding } \\
\text { Kidney insufficiency } \\
\text { Platelet inhibiting [7, } \\
13]\end{array}$ \\
\hline
\end{tabular}

anticytokine-acting or metabolic change-affecting drugs and anabolic steroids can be used to counteract anorexia, inflammation, and muscle loss. However, the potential positive effects of the pharmaceutical substances are offset by undesirable side effects ([7]; Table 2).

Physical training programs that are based on the individual performance should be integrated into the treatment, as exercise has been shown to have many positive effects (e.g., anti-inflammatory effects, counter insulin resistance, decrease oxidative stress, reduce depressive symptoms, increase anabolic hormones) [1].

Regular dietary consultations and check-ups as well as measuring of muscle mass should be carried out. In end-of-life care, symptoms such as hunger or thirst must be treated, while continued normal food intake lacking allowances for end-of-life care would put an unacceptable burden on the dying person [1, 2].

\section{Take-Home Message}

- Every cancer patient should be screened for malnutrition.

- Adequate nutritional therapy and regular dietetic counselling should be offered.

- Cachectic patients should receive additional support.

Funding Open access funding provided by FH St. Pölten University of Applied Sciences.

Conflict of interest A. Beirer declares that she has no competing interests.

Open Access This article is licensed under a Creative Commons Attribution 4.0 International License, which permits use, sharing, adaptation, distribution and reproduction in any medium or format, as long as you give appropriate credit to the original author(s) and the source, provide a link to the Creative Commons licence, and indicate if changes were made. The images or other third party material in this article are included in the article's Creative Commons licence, unless indicated otherwise in a credit line to the material. If material is not included in the article's Creative Commons licence and your intended use is not permitted by statutory regulation or exceeds the permitted use, you will need to obtain permission directly from the copyright holder. To view a copy of this licence, visit http://creativecommons.org/licenses/by/4.0/.

\section{References}

1. Arends J. Ernährung von Tumorpatienten. Aktuel Ernahrungsmed. 2012;37(2):91-106.

2. Arends J, Baracos V, Bertz H, BozzettiF, Calder PC, Deutz NE, et al. ESPEN expert group recommendations for action against cancer-related malnutrition. Clin Nutr. 2017;36:1187-96.

3. Castillo-Martinez L, Castro-Eguiluz D, Copca-Mendoza ET, Pérez-Camargo DA, Reyes-Torres CA, Alejandra-Damasco Ávila E, et al. Nutritional assessment tools for the identification of malnutrition and nutritional risk associated with cancer treatment. Rev Invest Clin. 2018;70:121-5.

4. Arends J, Bertz H, Bischoff SC, Fietkau R, Herrmann HJ, Holm E, et al. Klinische Ernährung in der Onkologie S3 Leitlinie. AktuelErnahrungsmed. 2015;40:1-74.

5. Jensen GL, Mirtallo J, Compher C, Dhaliwal R, Forbes A, Grijalba RF, et al. Adult starvation and disease-related malnutrition: a proposal for etiology-based diagnosis in the clinical practice setting from the international consensus. Clin Nutr. 2010;29:151-3.

6. Valentini L, Volkert D, Schütz T, Ockenga J, Pirlich M, Druml W, et al. Leitlinie der Deutschen Gesellschaft für Ernährungsmedizin (DGEM). Aktuel Ernahrungsmed. 2013;38:97-111.

7. Hauner H, Martigoni M. Manual Ernährung in der Onkologie Empfehlung zur Diagnostik, Therpie und Nachsorge. München: W.Zuckerschwerdt Verlag; 2018.

8. WinterJE, MacInnis RJ, Wattanapenpaiboon N, NowsonCA. BMI andall-causemortalityinolder adults: ameta-analysis. Clin Nutr. 2014;99:875-90. 
9. CederholmT, BosaeusI, BarazzoniR, BauerJ,Van GossumA, KlekS, et al. Diagnostic criteria for malnutrition e an ESPEN consensus statement. Clin Nutr. 2015;34:335-40.

10. Ernährung ÖGf. BMI-Klassifikation für Erwachsene. 2019. https://www.oege.at/index.php/bildung-information/ ernaehrung-von-a-z/1757-bmi. Accessed 25 July 2020.

11. Lückerath E, Müller SD. Diätetik und Ernährungsberatung Das Praxisbuch. 5th ed. Stuttgart: Karl F. Haug Verlag; 2013. p.214.

12. Aapro M, Arends J, Bozzetti F, Fearon K, Grunberg SM, Herrstedt J, et al. Early recognition of malnutrition and cachexia in the cancer patient: a position paper of a European school of oncology task force. Ann Oncol. 2014;25(8):1492-9.

13. Sadeghi M, Keshavarz-Fathi M, Baracos V, Arends J, Mahmoudi M, Rezaei N. Cancer cachexia: diagnosis, assessment, and treatment. Crit Rev Oncol Hematol. 2018;127:91-104.

14. Fearon K, Strasser F, Anker SD, Bosaeus I, Bruera E, Fainsinger RL, et al. Definition and classification of cancer cachexia: an international consensus. Lancet Oncol. 2011;12:489-95.

15. Evans WJ, Morley JE, Argilés J, Bales C, Baracos V, Guttridge D, et al. Cachexia: a new definition. Clin Nutr. 2008;27(6):793-9.

16. Fearon KC, Voss AC, Hustead DS. Definition of cancer cachexia: effect of weight loss, reduced food intake, and systemic inflammation on functional status and prognosis. AmJ Clin Nutr. 2006;83(6):1345-50.
17. Cruz-JentoftAJ, Bahat G, Bauer J, BoirieY, BruyèreO, Cederholm T, et al. Sarcopenia: revised European consensus on definition and diagnosis. Age Ageing. 2019;48(1):16-31.

18. Bauer J, Money J, Schols AM, Ferrucci L, Cruz-Jentoft AJ, Dent E, et al. Sarcopenia: a time for action. SCWD position paper. J Cachexia Sarcopenia Muscle. 2019; https://doi. org/10.1002/jcsm.12483.

19. Sheean P, Gonzalez MC, Prado CM, Mc Keever L, Hall AM, Braunschweig CA. American society for parenteral and enteral nutrition clinical guidelines: the validity of body composition assessment in clinical populations. JPEN J Parenter Enteral Nutr. 2020; https://doi.org/10.1002/jpen. 1669.

20. Erickson N, Schaller N, Berling-Ernst AP, Bertz H. Ernährungspraxis Onkologie. Stuttgart: Schattauer; 2017.

Publisher's Note Springer Nature remains neutral with regard to jurisdictional claims in published maps and institutional affiliations.

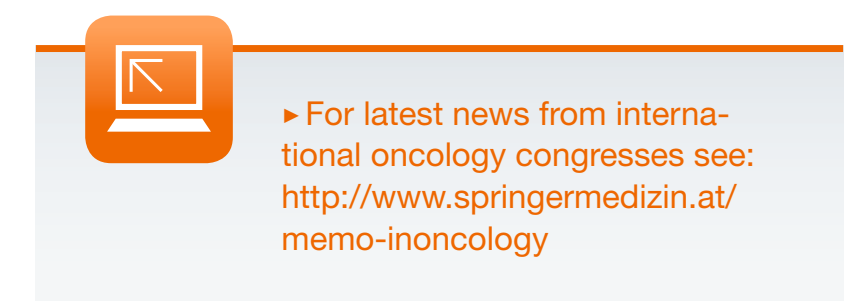

